* Artigo Original

\title{
O Programa Nacional de Melhoria do Acesso e da Qualidade da Atenção Básica: Reflexões sobre o seu desenho e processo de implantação
}

\section{Hêider Aurélio Pinto}

Médico, Especialista em Saúde Coletiva, Diretor do Departamento de Atenção Básica do Ministério da Saúde.

\section{Allan Sousa}

Mestre em Ciência Política, Coordenador-Geral de Acompanhamento e Avaliação da Atenção Básica do Ministério da Saúde

\section{Alexandre Ramos Florêncio}

Mestre em Saúde Coletiva, Diretor Adjunto do Departamento de Atenção Básica do Ministério da Saúde

DOI:10.3395/reciis.v6i2.Sup1.624pt

\section{Resumo}

O presente artigo descreve as principais características e elementos constituintes do Programa Nacional de Melhoria do Acesso e da Qualidade da Atenção Básica, além de avaliar o processo inicial de sua implantação a partir da descrição de dados sobre a adesão dos municípios e das equipes de atenção básica. $O$ artigo mostra como o PMAQ se insere e se relaciona com o conjunto de estratégias prioritárias definidas pela Política Nacional de Atenção Básica e com outros movimentos mais amplos de reorientação do modo como se organiza o Sistema Único de Saúde. São ainda apresentadas as quatro fases que organizam o programa, adesão e contratualização; desenvolvimento; avaliação externa; e recontratualização e dados sobre a adesão ao programa e a utilização da ferramenta autoavaliativa ofertada pelo Ministério da Saúde.

\section{Introdução}

A Portaria 1.654 do Ministério da Saúde, publicada em 19 de julho de 2011, criou o Programa Nacional de Melhoria do Acesso e da Qualidade (PMAQ) e vinculou pela primeira vez o repasse de recursos à implantação e alcance de padrões de acesso e de qualidade pelas equipes de atenção básica (EAB). Essa medida representa um processo profundo de mudança na lógica de repasse de recursos para a Atenção Básica $(A B)$ e anuncia mudanças semelhantes no financiamento do Sistema Único de Saúde (SUS) como um todo.

Além disso, é um componente da nova Política Nacional de Atenção Básica (PNAB) cujo sucesso está condicionado à sua capacidade de mobilizar os atores locais em prol da mudança das condições e práticas de atenção, gestão e participação orientados por diretrizes pactuadas 
nacionalmente. Depende fundamentalmente do fomento de espaços de diálogo/problematização/negociação/gestão da mudança entre equipes, gestores e usuários, com potência de produzir mudanças concretas na realidade cotidiana dos serviços.

Este artigo pretende descrever o desenho dessa política, que apresenta razoável grau de ineditismo e complexidade, e avaliar seu processo inicial de implantação a partir da descrição de dados sobre a adesão dos municípios e das EAB.

\section{O PMAQ como principal estratégia do "Saúde Mais Perto de Você"}

O Ministério da Saúde declara que no "Saúde Mais Perto de Você", o modo como tem se referido, tanto ao conjunto de iniciativas da nova PNAB, quanto à rede de Unidades Básicas de Saúde (UBS), o PMAQ é a "principal estratégia indutora de mudanças nas condições e modos de funcionamento das UBS", almejando a permanente e progressiva ampliação do acesso e da qualidade "das práticas de gestão, cuidado e participação" na AB (BRASIL, 2011d)

A amplitude e ousadia dos objetivos do PMAQ pode ser percebida ao ler suas diretrizes expostas na Portaria 1.654:

"I - construir parâmetro de comparação entre as equipes de saúde da atenção básica, considerando-se as diferentes realidades de saúde;

II - estimular processo contínuo e progressivo de melhoramento dos padrões e indicadores de acesso e de qualidade que envolva a gestão, o processo de trabalho e os resultados alcançados pelas equipes de saúde da atenção básica;

III - transparência em todas as suas etapas, permitindo-se o contínuo acompanhamento de suas ações e resultados pela sociedade;

IV - envolver, mobilizar e responsabilizar os gestores federal, estaduais, do Distrito Federal e municipais, as equipes de saúde de atenção básica e os usuários num processo de mudança de cultura de gestão e qualificação da atenção básica;

V - desenvolver cultura de negociação e contratualização, que implique na gestão dos recursos em função dos compromissos e resultados pactuados e alcançados;

VI - estimular a efetiva mudança do modelo de atenção, o desenvolvimento dos trabalhadores e a orientação dos serviços em função das necessidades e da satisfação dos usuários; e

VII - caráter voluntário para a adesão tanto pelas equipes de saúde da atenção básica quanto pelos gestores municipais, a partir do pressuposto de que o seu êxito depende da motivação e proatividade dos atores envolvidos." (BRASIL, 2011c, grifos dos autores).

Para tentar alcançar esses objetivos o PMAQ promoveu uma mudança profunda no financiamento da $A B$ vinculando parte importante do repasse de recursos à implantação de "padrões" que indicariam a ampliação do acesso aos serviços, a melhoria das condições de trabalho e da qualidade da atenção e o investimento no desenvolvimento dos trabalhadores. Com a criação do "Componente de Qualidade" do Piso de Atenção Básica (PAB) Variável os municípios passaram a ter a possibilidade de até dobrar o recurso recebido por equipe, caso alcancem um desempenho "ótimo" naquilo que o PMAQ toma como objeto de contratualização e avaliação, os "padrões" (BRASIL, 2012d). 
Em Pinto et al. (2012) temos a descrição do novo desenho do financiamento da $A B$ e uma indicação da prioridade desta agenda para o Governo Federal. No mesmo artigo há previsão de que, em 2013, 15\% do PAB Variável esteja comprometido com o PMAQ, valor expressivo que chegaria perto de $\mathrm{R} \$ 1,5$ bilhões.

A "qualidade", citada tantas vezes nos documentos oficiais que tratam do tema, é compreendida como uma construção social, produzida com base nas referências dos sujeitos envolvidos, que varia de acordo com o contexto histórico, político, econômico, tecnológico e cultural e com os conhecimentos acumulados sobre o tema (BRASIL, 2011c, 2011d). Em certo momento é definida como "o grau de atendimento a padrões de qualidade estabelecidos frente às normas, protocolos, princípios e diretrizes que organizam as ações e práticas, assim como aos conhecimentos técnicos e científicos atuais, respeitando valores culturalmente aceitos e considerando a competência dos atores" (BRASIL, 2011e).

O chamado "padrão de qualidade" é uma declaração da qualidade esperada e expressa afirmativamente o sentido da política produzida nos espaços tripartite de governança do SUS. Busca afirmar os princípios da "integralidade, universalidade, equidade e participação social" (BRASIL, 2011e) e enfrentar os nós críticos debatidos e assumidos como "situação a ser superada" pelo "Saúde Mais Perto de Você". As dimensões e padrões propostos pelo PMAQ operam como a afirmação de diretrizes e de uma caminhada para a superação dos problemas priorizados. A qualidade não é apreendida como topos ou platô e sim como "fluxo" e "movimento" devendo, por isso, ser fruto da atuação dos atores implicados, com capacidade de mudar o cenário e, portanto, exigir permanente adaptação e evolução da Política, de suas estratégias e instrumentos:

"é esperado que o PMAQ seja constantemente aperfeiçoado, de modo a contemplar, progressivamente, a diversidade dos cenários em que será implantado; a necessidade de adequação dos critérios, parâmetros e ferramentas de avaliação e gestão, com vistas às novas demandas e desafios da Política de Atenção Básica e ao momento histórico de implantação do SUS; e a necessidade de revisão de conceitos, metodologias e ferramentas, com base no aprendizado institucional da implantação do PMAQ e na colaboração dos diferentes atores envolvidos." (BRASIL, 2011e)

\section{O PMAQ como parte de movimentos mais profundos}

O PMAQ, por sua vez, é um movimento articulado a outros três mais amplos do Ministério da Saúde, tendo sido formulado junto com eles e se antecipado um pouco na implantação.

Não pode ser compreendido fora do contexto de efetiva valorização e de definição do papel da $A B$ no conjunto da rede que contou com a publicação de diversos atos normativos. A regulamentação da Lei 8.080, por meio do Decreto 7.508, de 29 de junho de 2011, define a $A B$ como "porta de entrada" do sistema, como elemento essencial e indispensável de uma região de saúde, como ordenadora do acesso "universal e igualitário" às ações e serviços de saúde da rede (BRASIL, 2011b). As portarias que instituíram as "redes de atenção" tiveram o cuidado de se descrever na $A B$ reconhecendo claramente seu papel de porta de entrada e primeiro contato.

Observando como o PMAQ se propõe a induzir e avaliar papéis e ações da $A B$ como parte das redes prioritárias (BRASIL, 2012b) fica claro que ele pretende ser uma estratégia que sintetiza 
tanto o esforço de afirmação da $A B$ como porta de entrada acolhedora e resolutiva para 0 conjunto das necessidades de saúde, quanto a criação das condições concretas para que ela garanta e coordene a continuidade do cuidado nas linhas de cuidado priorizadas nas redes.

Um segundo movimento que dá sustentação e ao qual o PMAQ está articulado é o redesenho da governança sistêmica e do financiamento do SUS conforme o Decreto Presidencial 7.508 de 29 de junho de 2011. Entre outros tantos avanços, o Decreto e seus instrumentos, em especial o Contrato Organizativo de Ação Pública (COAP), traz a possibilidade de avançar num modo de financiamento mais completo e adequado às singularidades dos contextos e especificidades locais e regionais. O Decreto fala em "avaliação do desempenho da prestação das ações e dos serviços", em "responsabilidades assumidas" pelo ente envolvendo pactuação de "indicadores e metas de saúde", "estratégias para a melhoria das ações e serviços de saúde", "critérios de avaliação dos resultados e forma de monitoramento permanente" e diz ainda que o "Ministério da Saúde poderá instituir formas de incentivo ao cumprimento das metas de saúde e à melhoriadas ações e serviços de saúde" (BRASIL, 2011b).

Pinto, Koerner et al (2012) nos mostraram que o desenho do novo financiamento da PNAB, implantado em 2011, guarda coerência e é aderente ao que pretende ser implantado com o COAP e seus instrumentos. Destacamos que o PMAQ responde justamente pelo componente do novo financiamento da $A B$ que leva em conta a contratualização de compromissos, 0 monitoramento de indicadores e o alcance de resultados.

Um terceiro movimento é o Programa de Avaliação para a Qualificação do SUS, um modelo de avaliação de desempenho dos sistemas de saúde, nos três níveis de governo, que pretende mensurar os possíveis efeitos da política de saúde com vistas a subsidiar a tomada de decisão, garantir a transparência dos processos de gestão do SUS e dar visibilidade aos resultados alcançados, além de fortalecer o controle social e o foco do sistema de saúde nos usuários (BRASIL, 2011a). O PMAQ é parte integrante desse esforço que reúne também diversas outras iniciativas, como o Índice de Desempenho do SUS (IDSUS), todas coerentes com os objetivos do programa.

\section{O PMAQ e a aposta na produção de movimentos: primeira fase}

O PMAQ está organizado em quatro fases que se "complementam e que conformam um ciclo contínuo de melhoria do acesso e da qualidade" (BRASIL, 2011d). A primeira é chamada de "Adesão e Contratualização", a segunda de "Desenvolvimento", a terceira de "Avaliação Externa" e a quarta, que na verdade representa o começo de um novo ciclo, denomina-se "Recontratualização".

Não pretendemos apresentar o desenho estático das fases do PMAQ, claras na Portaria 1.654, nem colocar todo o foco na avaliação externa e no que ela determina em termos de repasse de recursos. Essa abordagem percebe mais a ação homogênea, normalizada nacionalmente, a que se repete, superfície de registro (DELEUZE et al., 2003). Deixa escapar justamente o pólo dinâmico e singular do programa, superfície de produção (DELEUZE et al, 2003): as ações de mudança de equipes de cuidado e da gestão municipal que ocorrem no cotidiano dos serviços. Tentaremos captar o movimento e explicitar apostas estratégicas contidas nos diversos documentos e instrumentos do programa. Para nós está claro que a finalidade da fase de 
contratualização e da terceira, avaliação externa e certificação, é promover a segunda fase, motivando o protagonismo e o esforço de mudança das EAB e da gestão municipal.

A primeira fase do PMAQ é descrita como "a etapa formal de adesão ao Programa", mediante "contratualização de compromissos e indicadores a serem firmados" entre as EAB e os gestores municipais, e desses com o Ministério da Saúde "num processo que envolve pactuação regional e estadual e a participação do controle social" (BRASIL, 2011d). O caráter voluntário da adesão está associado à ideia de que a qualificação do serviço e mudanças das práticas só se concretizarão em "ambientes nos quais os trabalhadores e gestores sintam-se motivados e se percebam essenciais para o seu êxito" (BRASIL, 2011d). É um dispositivo que convoca ao envolvimento e protagonismo dos diversos atores e amplia a possibilidades de construção de ambientes participativos dialógicos, nos quais gestores, trabalhadores e usuários se mobilizam para se comprometerem com objetivos comuns.

Cada EAB para aderir teve que assinar um "Termo de Compromisso" no qual se comprometeu em: (a) seguir diretrizes organizantes do processo de trabalho; (b) observar regras de funcionamento do programa; (c) implantar dispositivos de acesso, co-gestão, autoavaliação, planejamento e avaliação relacionados a cada uma das fases posteriores; (d) ser monitorada por seis meses a partir de quarenta e sete indicadores do Sistema de Informação da Atenção Básica (SIAB); e (e) passar por um processo de avaliação que inclui a autoavaliação, o desempenho em vinte e quatro indicadores e a avaliação in loco realizada por avaliadores externos que visitariam cada equipe na terceira fase do programa.

A adesão e contratualização individualizada por EAB tentou introduzir um dispositivo concreto de viabilização do reconhecimento intersubjetivo dos indivíduos que devem se responsabilizar pelo conjunto de ações capazes de promover a ampliação do acesso e da qualidade da atenção básica.

O Município, por sua vez, ao aderir passou a receber imediatamente vinte por cento do Componente de Qualidade do PAB por equipe aderida. Esse repasse segue até a realização da avaliação externa e conclusão da certificação da equipe quando então esse percentual passa a depender do desempenho alcançado por cada $E A B$, podendo ser de cem por cento no caso de desempenho "ótimo" ou a suspensão de qualquer repasse do Componente no caso de desempenho insatisfatório.

A adesão dos gestores municipais incluiu o cadastramento das $E A B$, após prévia adesão das EAB como dito acima, e a assinatura de Termo no qual assumiu compromissos relacionados: " (a) à aplicação dos recursos do Componente de Qualidade do PAB Variável; (b) à realização de ações para a melhoria das condições de trabalho das $E A B$; (c) à estruturação da gestão da $A B$ garantindo "condições de funcionamento da equipe de gestão responsável pela implantação local do Programa" e envolvendo a mesma no apoio institucional às EAB para realização da autoavaliação, para a instituição de mecanismos de gestão colegiada nas UBS e de avaliação e monitoramento de indicadores, para o desenvolvimento de ações de educação permanente e execução ações compartilhadas de superação dos problemas identificados e alcance dos resultados pactuados (BRASIL, 2011d).

Merece destaque a tentativa do Programa de constituir movimentos de implicação e dispositivos de gestão colegiada que possam gerir a mudança. Aposta-se no fomento de uma dinâmica que propicie a constituição de espaços de negociação e implicação dos atores 
envolvidos, buscando claramente mobilizá-los através da possibilidade de terem seus interesses, necessidades e desejos contemplados.

O objetivo explícito é que isso se consolide como modus operandi, como cultura de negociação e gestão comprometida com a mudança do modelo de atenção e gestão, o desenvolvimento da equipe e a orientação dos serviços em função das necessidades de saúde dos usuários. Ao mesmo tempo, o Programa busca interferir de algum modo no que será negociado nesse espaço ao propor conteúdos e repertórios a essa negociação. Faz isso ao apontar a direção do movimento de qualificação através de indicadores a serem alcançados e padrões de acesso e qualidade a serem implantados.

\section{O PMAQ e a aposta na produção de movimentos: segunda fase}

A segunda fase do PMAQ é compreendida como a etapa na qual se daria o desenvolvimento de ações, realizadas fundamentalmente pelas EAB e gestão municipal, mas com o apoio das gestões estaduais e Ministério da Saúde, "com o intuito de promover os movimentos de mudança da gestão, do cuidado e da gestão do cuidado que produzirão a melhoria do acesso e da qualidade da $A B^{\prime \prime}$ (BRASIL, 2011d). Há uma aposta em quatro estratégias nessa fase: na autoavaliação, no monitoramento, na educação permanente e no apoio institucional.

A autoavaliação é tida como "ponto de partida da fase de desenvolvimento", propondo que o processo se inicie "pela identificação e reconhecimento, pelas próprias equipes, das dimensões positivas e também problemáticas do seu trabalho, produzindo sentidos e significados potencialmente facilitadores/mobilizadores de iniciativas de mudança e aprimoramento" (BRASIL, 2011d). Espera-se que funcione como um dispositivo que provoque o coletivo a interrogar o instituído (ALTOÉ, 2004), a colocar em análise seu processo, relações e condições de trabalho. Aposta-se na ampliação da capacidade de auto-análise (BAREMBLITT, 1998) para que se amplie também a capacidade de co-gestão daquele coletivo organizado para a produção (CAMPOS, 2000) de modo que consiga negociar e planejar modos de superar problemas e alcançar objetivos desejados e pactuados.

Mais uma vez a estratégia do PMAQ aposta em dispositivos que possam provocar o espaço de diálogo, negociação e gestão das mudanças que o programa buscou garantir na fase de contratualização. Espaço que idealmente reuniria a equipe, por diversas vezes contaria com membros da gestão municipal responsáveis por aquelas EAB, se possível apoiadores, e eventualmente com a participação da comunidade (BRASIL, 2011d, 2011e, 2012a). A insistência na participação ativa de referências da gestão municipal, teria o objetivo de fortalecer uma análise e ação compartilhada com maior potencial de mudança da situação nominada como problema.

O Ministério da Saúde ofertou a ferramenta "Autoavaliação para a Melhoria do Acesso e da Qualidade (AMAQ)" que poderia "ser combinada com outras ferramentas, cabendo aos gestores municipais e às $E A B$ definirem o uso (...) que se adeque à sua necessidade $e$ realidade" (BRASIL, 2011e). Trata-se de uma ferramenta extensa que se propõe a abordar múltiplas dimensões e que necessariamente provoca a identificação de muito mais problemas que a EAB poderia tomar como centro prático de ação (CECÍLIO, 1997, 2003). Daí o reforço do material (BRASIL, 2011e) em propor uma dinâmica afeita à gestão estratégica (MATUS, 1993; CECÍLIO, 1997, 2003; CAMPOS, 2000), na qual a ferramenta cumpre o papel de alimentar o 
diálogo do grupo para que ele possa eleger os problemas e pactuar ações conforme suas explicações, prioridades, interesses, disposição e capacidade de ação.

Para que a autoavaliação se fortaleça como um processo permanente a orientar a tomada de decisões, o PMAQ propõe que ela seja enriquecida pelo monitoramento dos indicadores propostos pelo programa (BRASIL, 2011d) que teriam entre seus objetivos "orientar o processo de negociação e contratualização de metas e compromissos entre EAB e gestor municipal" e "subsidiar a definição de prioridades e programação de ações".

O Ministério da Saúde realizou em 2011 mudanças no SIAB para que pudesse acessar e acompanhar os dados do sistema no seu nível maior de desagregação, a equipe. Com isso, o programa apostou na possibilidade de institucionalização de uma prática permanente de monitoramento e avaliação, tanto pelas EAB quanto pela gestão municipal, com capacidade de "permitir a identificação (...) de desafios, o reconhecimento dos resultados alcançados, a efetividade ou necessidade de aperfeiçoamento das estratégias de intervenção" e de democratizar e dar "transparência" à gestão da AB fortalecendo a participação do usuário, por meio da "publicização de metas, padrões de qualidade e resultados alcançados" (BRASIL, 2011d).

A escolha dos quarenta e sete indicadores obedeceu a três critérios. Ficou restrita àqueles que podiam ser monitorados e avaliados por meio do SIAB "por esse ser o único sistema disponível para a alimentação e acompanhamento das equipes de maneira individualizada" (BRASIL, 2011d). Priorizou-se indicadores historicamente pactuados no âmbito do Pacto Pela Saúde e utilizados na composição do IDSUS e buscou-se articular com a prioridades definidas pelas três esferas de governo (BRASIL, 2011d).

A imagem que o documento (BRASIL, 2011d) sugere é a de um coletivo que faz uso permanente da autoavaliação e do monitoramento para se apropriar do processo de trabalho e de seus resultados, ampliando assim a motivação e a satisfação com o mesmo e a capacidade de diálogo e ação compartilhada com a gestão e a comunidade.

O Ministério, através de processos de formação, financiamento, orientação técnica e até mesmo valorização na avaliação externa do $\mathrm{PMAQ}$, passou a estimular que as gestões municipais investissem na adoção do apoio institucional (CAMPOS, 2003) como tecnologia de gestão e na oferta de processos de educação permanente (CECCIN, 2005) articulados às ações de mudança do programa.

O programa sugere que o "saber e fazer em educação permanente (EP) seja encarnado na prática concreta dos serviços de saúde", pois a "mudança do modelo de atenção impõe a necessidade de qualificação dos serviços de saúde e de seus profissionais e as mudanças no processo de trabalho em saúde passam a exigir de seus atores (trabalhadores, gestores e usuários) maior capacidade de intervenção e autonomia para que possam contribuir para o estabelecimento de práticas transformadoras" (BRASIL, 2011d). Propõe que a EP seja vista como uma importante "estratégia de gestão" com grande potencial provocador de mudanças na micropolítica (MERHY, 2002) do cotidiano dos serviços, "bastante próximo dos efeitos concretos das práticas de saúde na vida dos usuários" (BRASIL, 2011d).

O PMAQ propõe uma articulação entre os processos de EP e as estratégias de apoio institucional (AI) para "aumentar as alternativas para o enfrentamento das dificuldades 
vivenciadas pelos trabalhadores em seu cotidiano" (BRASIL, 2011d). Sugere que o AI seja pensado como uma "função gerencial que busca a reformulação do modo tradicional de se fazer" gestão em saúde.

O programa tenta induzir a criação de equipes de AI (BRASIL, 2011d, 2011e, 2012a), "com dimensionamento adequado do número de equipes por apoiador", lembrando a necessidade de construção "de vínculo entre os mesmos" e de agendas regulares de encontros (BRASIL, 2011d).

Essas equipes de AI deveriam assumir como objetivo a mudança nas organizações, tomar como "matéria-prima os problemas e tensões do cotidiano" e operar como "forte disparador de processos que propiciem o suporte ao movimento de mudança deflagrado por coletivos", buscando fortalecê-los, reconhecendo e potencializando seus esforços, reforçando "processos de subjetivação que produzam liberdade e compromisso" (BRASIL, 2011d).

Em síntese, podemos dizer que as equipes de atenção e gestão, com a tarefa de imprimir mudanças na realidade concreta, deverão construir pactos e ações, disparar movimentos que articulem avaliação, planejamento, educação permanente, gestão do trabalho, qualificação do processo de trabalho e monitoramento de resultados numa excelente oportunidade de superar modos de ação que fragmentados perdem grande parte de sua potência.

A segunda fase receberia um corte artificial com a realização dos processos de avaliação externa previstos para serem realizados após seis meses da adesão ao programa. Falamos de corte artificial, pois na realidade não tem como encerrá-la sem interromper também as próprias ações de atenção e gestão das equipes de cuidado e de coordenação da $A B$ no município.

\section{O PMAQ e a aposta na produção de movimentos: terceira fase}

A terceira fase é o momento de realização da Avaliação Externa que "consiste no levantamento de informações para análise das condições de acesso e de qualidade das $E A B^{\prime \prime}$ e para reconhecimento e valorização dos "esforços e resultados" dessas EAB e dos gestores municipais na qualificação da $A B$ (BRASIL, 2012a). Essa avaliação gerará um escore que conforme as regras da portaria 1.654 , de 19 de julho de 2011 , e com as alterações instituídas pela portaria 866, de 03 de maio de 2012, resultará numa certificação que, por sua vez, determinará o percentual do componente de qualidade que será repassado mensalmente ao fundo municipal de saúde pelo Ministério da Saúde.

O escore leva em conta três componentes. Representando dez por cento do total do escore, numa lógica de tudo ou nada, está a simples realização da autoavaliação pela EAB, independente daquilo que se responda. Outros vinte por cento correspondem ao desempenho da $E A B$ nos 24 indicadores monitorados durante toda a fase de Desenvolvimento (BRASIL, 2011c, 2011d).

Por fim, os setenta por cento restantes resultam da aplicação dos instrumentos de avaliação da terceira fase que estão organizados em quatro módulos conforme o método de coleta das informações: módulo I - observação na UBS; módulo II - entrevista com o profissional da EAB e verificação de documentos na UBS; módulo III - entrevista com o usuário na UBS; e módulo 
IV - módulo on line que, informado pela gestão municipal e pela EAB, complementa os demais módulos (BRASIL, 2012a).

Os padrões foram distribuídos em cinco dimensões. Na dimensão "gestão municipal para desenvolvimento da $A B$ " se avalia fundamentalmente a estrutura e equipes de gestão da $A B$ do município e o apoio que ela dá às EAB aderidas ao programa (BRASIL, 2012a). Trata-se também de uma checagem de compromissos assumidos pelo gestor municipal na contratualização da primeira fase do programa.

$\mathrm{Na}$ "estrutura e condições de funcionamento da UBS" são verificadas, além da infraestrutura, acessibilidade, ambiência e condições de trabalho, a disponibilidade de equipamentos, insumos e medicamentos importantes para a atenção à saúde com foco nas linhas de cuidado priorizadas (BRASIL, 2012a).

$\mathrm{Na}$ "valorização do trabalhador" avalia-se a formação dos membros da EAB, o investimento feito pela gestão municipal no desenvolvimento profissional, formação e educação permanente da $E A B$, a garantia de diretos trabalhistas, vínculos de trabalho, existência de carreira e implantação de dispositivos desejáveis de gestão do trabalho (BRASIL, 2012a).

No "acesso e qualidade da atenção e organização do processo de trabalho" avalia-se na perspectiva do profissional e do usuário: o acesso; a implantação de dispositivos como o acolhimento, agenda compartilhada, ferramentas de gestão do cuidado e gestão colegiada do processo de trabalho; além de avaliar também padrões de qualidade relacionadas à atenção das linhas de cuidado priorizadas, dentre tantos outros (BRASIL, 2012a).

Por fim, há ainda a dimensão "utilização, participação e satisfação do usuário" que avalia a utilização dos serviços pelo usuário, várias dimensões de sua satisfação e a implantação de dispositivos e espaços de participação dos usuários e de exercício do controle social (BRASIL, 2012a).

Com tudo isso, é importante destacar três pontos. Ao focar também numa dimensão micro e meso do processo de trabalho, o PMAQ ousa mais uma vez: busca estimular desde uma política nacional a implantação de dispositivos que sejam provocadores de mudança no processo de trabalho cotidiano. Assim, trata-se de uma política nacional que estimula os atores implicados a implantar dispositivos como acolhimento, agenda compartilhada, gestão do cuidado, remuneração por desempenho, gestão colegiada, conselhos locais de saúde, etc. Assim, o PMAQ busca estimular a reflexão crítica sobre o instituído e provocar o coletivo a agir ativamente pela mudança do cotidiano, mas não comete excesso de definir formas. Antes o contrário, induz todo o tempo que as equipes "inovem", "criem", "experimentem" conforme sua realidade e possibilidade e que compartilhem.

Merece destaque também a preocupação da avaliação não só com a estrutura e o processo, mas com os resultados mais imediatos da atenção à saúde e com a entrada em cena da perspectiva e avaliação do usuário (BRASIL, 2012a). Os instrumentos contemplam também os resultados concretos obtidos no acesso e na qualidade da atenção a grupos específicos, como as mulheres, crianças, gestantes, pessoas com condições crônicas, pessoas com transtornos mentais etc. E ao combinar isso com a vinda para o centro da cena a perspectiva do usuário, tanto sobre os resultados como sobre os efeitos diretos da mudanças, ele aponta para a 
produção de um material com grande capacidade de comunicar com o público em geral, de dizer às pessoas que UBS eles têm perto de sua casa.

Por fim, a avaliação se propõe a medir o desempenho em padrões de qualidade cuja mudança encontra-se sob governabilidade (TESTA, 1992) distinta entre EAB, gestão municipal de saúde e prefeitura, por exemplo. Podemos sugerir como exemplo que a estrutura física, a conectividade e o plano de carreiras exigiriam gestões do prefeito; a garantia de insumos, equipamentos e normas de funcionamento das UBS do secretário; outras tantas da equipes de atenção à saúde e da equipe de gestão descentralizada. Com isso, argumentamos que a avaliação não é "da equipe", ela é "por equipe" porque avalia uma série de elementos com responsabilidades compartilhadas entre o conjunto de atores locais, mas toma como unidade de análise a EAB e seu local de trabalho, a UBS.

Assim, é claro que interessa diretamente à EAB a melhoria das condições de trabalho, a desprecarização de seu vínculo, a melhor estrutura da UBS, a maior disponibilidade de instrumentos, etc. e todas essas dimensões estão mais sobre a governabilidade do gestor que dela mesma. Essa percepção não está muito clara nos documentos e é importante que o modo de divulgação dos resultados leve isso em conta para não cometer o erro de atribuir a responsabilidade do desempenho a quem está tendo desempenho baixo, justamente por não estar tendo garantidas suas condições mínimas.

Vale destacar que em todos os módulos da avaliação externa, há questões que serão utilizadas para a certificação das equipes e outras que objetivam o levantamento de informações para orientar o aperfeiçoamento das políticas de saúde. Esse diagnóstico, portanto, tem a pretensão de: viabilizar a certificação de todas as EAB do PMAQ; realizar o Censo de todas as UBS do Brasil, aderidas ou não ao PMAQ; "conhecer em escala e profundidade, inédita, as realidades e singularidades da $A B$ no Brasil (...) contribuindo para o planejamento" e elaboração de "estratégias adequadas às diferenças dos territórios, promovendo maior equidade nos investimentos dos governos federal, estadual e municipal" (BRASIL, 2012a)

\section{O PMAQ e a aposta na produção de movimentos: quarta fase}

A quarta fase é fase de conexão, é fase de re-processamento, de re-início, de recontratualização. Parece exigir um momento nacional tripartite de balanço e de ajuste de trajetória, ao mesmo tempo que tem sua dimensão local de repactuação de regras e de incremento nos objetivos do movimento de mudança. Segundo o programa, "a cada ciclo (...) novos parâmetros de qualidade podem ser definidos, induzindo avanços na direção do que se espera em termos de desenvolvimento da gestão, das equipes e do alcance dos resultados de saúde da população" (BRASIL, 2011d). Aponta-se também para a combinação entre elenco de padrões únicos nacionais e "pacotes" específicos de padrões que poderiam ser escolhidos pelas EAB conforme suas prioridades e necessidades (BRASIL, 2011d).

De todas as fases, a quarta sem dúvida é sobre a qual há menos descrição, talvez um indicativo de que ela está ainda por ser formulada, aguardando "acontecer", em função das respostas que the serão exigidas pelo fruto de todo esse processo. 


\section{A adesão e participação de municípios e equipes no PMAQ}

Considerando que não são "triviais" as exigências e compromissos necessários à adesão, os números alcançados são expressivos e impressionam pela alta capacidade de convocação do Programa.

Os municípios fizeram todas as etapas de sua adesão através do Sistema de Gestão de Programas do Departamento de Atenção Básica - o SGDAB. Nesse sistema on line puderam, ter acesso a todos os documentos do PMAQ, responder perguntas de identificação e de contratualização, baixar e imprimir os Termos de Compromisso, assinar os mesmos e fazer o carregamento eletrônico dos termos assinados. Responsáveis nos municípios geriam o acesso das EAB ao sistema podendo, portanto, acompanhar, apoiar e validar a adesão das EAB (BRASIL, 2011d). A adesão municipal só se concluiu depois de todas as EAB participantes concluírem sua adesão e estas serem validadas pelo gestor municipal.

Mesmo tendo menos de sessenta dias para a adesão, mais de $70 \%$ dos municípios brasileiros ingressaram no PMAQ (tabela 01). Uma adesão surpreendente para um programa novo, de adesão voluntária, que exigia uma série de pré-tarefas e a assunção de diversos compromissos para essa adesão.

Contudo, é possível notar claramente, apesar da forte adesão nacional, a existência de certa variabilidade quando comparamos os percentuais relativos por estado. Enquanto os estados do Ceará, Bahia, Santa Catarina, Sergipe, Rio de Janeiro e Amapá apresentam percentuais de adesão superiores a $80 \%$, os estados do Maranhão, Rondônia e Amazonas apresentam percentuais abaixo de $50 \%$, sendo que no Maranhão a adesão não chegou a $10 \%$ dos municípios.

Ao mesmo tempo, quando comparamos os percentuais de adesão por equipe, percebemos a permanência de uma expressiva variabilidade. No extremo superior encontramos os estados de Santa Catarina, Tocantins, Minas Gerais, Rio Grande do Sul e São Paulo, todos com percentuais acima de $60 \%$ de Equipes de Saúde da Família participando do programa. No limite inferior encontramos o Maranhão, Acre e Distrito Federal, com percentuais abaixo 30\% de equipes que aderiram ao programa. 
Tabela 01 - Total de municípios, municípios que aderiram ao PMAQ, percentual de municípios que aderiram ao PMAQ, total de equipes, equipes que aderiram ao PMAQ e percentual de equipes que aderiram ao PMAQ, por UF, Brasil, 2011

\begin{tabular}{|c|c|c|c|c|c|c|}
\hline UF & $\begin{array}{l}\text { Total de } \\
\text { Municípios }\end{array}$ & $\begin{array}{l}\text { Municípios } \\
\text { que Aderi- } \\
\text { ram ao } \\
\text { PMAQ }\end{array}$ & $\begin{array}{l}\text { \% de Muni- } \\
\text { cípios que } \\
\text { Aderiram } \\
\text { ao PMAQ }\end{array}$ & $\begin{array}{l}\text { Total de } \\
\text { Equipes }\end{array}$ & $\begin{array}{l}\text { Equipes que } \\
\text { Aderiram ao } \\
\text { PMAQ }\end{array}$ & $\begin{array}{l}\text { \% de Equipes } \\
\text { que Aderiram ao } \\
\text { PMAQ }\end{array}$ \\
\hline$A C$ & 22 & 11 & 50,0 & 137 & 32 & 23,4 \\
\hline $\mathrm{AL}$ & 102 & 67 & 65,7 & 758 & 340 & 44,9 \\
\hline AM & 62 & 26 & 41,9 & 515 & 173 & 33,6 \\
\hline AP & 16 & 13 & 81,3 & 144 & 52 & 36,1 \\
\hline BA & 417 & 372 & 89,2 & 2.744 & 1.564 & 57,0 \\
\hline CE & 184 & 171 & 92,9 & 1.869 & 920 & 49,2 \\
\hline $\mathrm{DF}$ & 1 & 1 & 100,0 & 111 & 28 & 25,2 \\
\hline ES & 78 & 51 & 65,4 & 576 & 323 & 56,1 \\
\hline GO & 246 & 174 & 70,7 & 1.151 & 684 & 59,4 \\
\hline MA & 217 & 20 & 9,2 & 1.782 & 115 & 6,5 \\
\hline MG & 853 & 656 & 76,9 & 4.337 & 2.944 & 67,9 \\
\hline MS & 78 & 51 & 65,4 & 449 & 184 & 41,0 \\
\hline MT & 141 & 87 & 61,7 & 584 & 227 & 38,9 \\
\hline PA & 143 & 100 & 69,9 & 948 & 371 & 39,1 \\
\hline PB & 223 & 173 & 77,6 & 1.248 & 625 & 50,1 \\
\hline $\mathrm{PE}$ & 185 & 132 & 71,4 & 1.867 & 1.025 & 54,9 \\
\hline PI & 224 & 136 & 60,7 & 1.092 & 371 & 34,0 \\
\hline PR & 399 & 301 & 75,4 & 1.807 & 1.007 & 55,7 \\
\hline RJ & 92 & 76 & 82,6 & 1.851 & 1.071 & 57,9 \\
\hline $\mathrm{RN}$ & 167 & 115 & 68,9 & 865 & 411 & 47,5 \\
\hline RO & 52 & 20 & 38,5 & 275 & 98 & 35,6 \\
\hline $\mathrm{RR}$ & 15 & 8 & 53,3 & 91 & 35 & 38,5 \\
\hline RS & 496 & 342 & 69,0 & 1.246 & 829 & 66,5 \\
\hline SC & 293 & 258 & 88,1 & 1.393 & 1.108 & 79,5 \\
\hline SE & 75 & 63 & 84,0 & 554 & 273 & 49,3 \\
\hline SP & 645 & 413 & 64,0 & 3.532 & 2.323 & 65,8 \\
\hline TO & 139 & 98 & 70,5 & 411 & 299 & 72,7 \\
\hline$B R$ & 5.565 & 3.935 & 70,7 & 32.337 & 17.432 & 53,9 \\
\hline
\end{tabular}

FONTE - Ministério da Saúde/Departamento de Atenção Básica

* Competência de Outubro de 2011

A enorme variação encontrada pode estar associada a um conjunto de fatores de contexto que podem servir como elementos de explicação para uma maior ou menor propensão a adesão ao PMAQ. No presente artigo selecionamos duas variáveis explicativas que, isoladamente ou 
interagindo entre si, podem nos apontar a existência de características societais e institucionais capazes de aumentar ou diminuir a probabilidade dos municípios optarem por participar do programa, quais sejam, o grau de desenvolvimento socioeconômico, medido pelo IDH, e o porte populacional dos municípios.

A tabela 02 mostra que, na medida em que se aumenta o grau de desenvolvimento socioeconômico, medido pelo IDH, maior o percentual relativo de municípios que aderiram ao PMAQ, revelando certa correlação entre as duas variáveis observadas.

Tabela 02 - Total de municípios, municípios que aderiram ao PMAQ e percentual de municípios que aderiram ao PMAQ, por IDH, Brasil, 2011

\begin{tabular}{|l|l|l|l|}
\hline IDH & $\begin{array}{l}\text { Total de } \\
\text { Municípios }\end{array}$ & $\begin{array}{l}\text { Municípios que Aderiram ao } \\
\text { PMAQ }\end{array}$ & $\begin{array}{l}\text { de Municípios que } \\
\text { Aderiram ao PMAQ }\end{array}$ \\
\hline Baixo & 2.505 & 1.747 & 69,7 \\
\hline Médio & 2.427 & 1.738 & 71,6 \\
\hline Alto & 575 & 450 & 78,3 \\
\hline Total & 5.565 & 3.935 & 70,7 \\
\hline
\end{tabular}

FONTE - Ministério da Saúde/Departamento de Atenção Básica

Da mesma maneira, quando cruzamos o porte populacional com o percentual relativo de municipalidades que aderiram ao PMAQ, notamos uma clara relação entre o tamanho do município e a sua propensão a participar do programa (tabela 03). Essa correlação assume um relevo mais nítido quando observamos que em municípios de pequeno porte a adesão ao PMAQ atingiu $67,6 \%$ dos casos, e em municípios de grande porte esse percentual chegou a $84,6 \%$.

Tabela 03 - Total de municípios, municípios que aderiram ao PMAQ e percentual de municípios que aderiram ao PMAQ, por porte populacional, Brasil, 2011

\begin{tabular}{|l|l|l|l|}
\hline Porte Populacional & $\begin{array}{l}\text { Total de } \\
\text { Municípios }\end{array}$ & $\begin{array}{l}\text { Municípios que } \\
\text { Aderiram ao PMAQ }\end{array}$ & $\begin{array}{l}\text { \% de Municípios que } \\
\text { Aderiram ao PMAQ }\end{array}$ \\
\hline Pequeno Porte & 3.914 & 2.646 & 67,6 \\
\hline Porte Intermediário & 1.294 & 987 & 76,3 \\
\hline Grande Porte & 3.57 & 302 & 84,6 \\
\hline Total & 5.565 & 3.935 & 70,7 \\
\hline
\end{tabular}

FONTE - Ministério da Saúde/Departamento de Atenção Básica

Obviamente, análises posteriores, a partir de uma verificação qualitativa já em curso, poderão nos indicar de maneira mais robusta os fatores que levaram a uma maior ou menor inclinação a participar do PMAQ. Por hora podemos levantar algumas hipóteses.

Em tese os municípios com maior grau de desenvolvimento socioeconômico e maior porte populacional reúnem maior capacidade institucional e melhores condições em dimensões importantes que são objeto de avaliação do PMAQ como infraestrutura, equipamentos, 
regularidade de insumos, estrutura e organização da gestão municipal e elementos relacionados à gestão da educação e do trabalho.

A expectativa dos gestores dos maiores e mais desenvolvidos municípios de terem melhores condições de participação e avaliação no PMAQ estava tão clara para os membros do Conselho Nacional das Secretarias Municipais de Saúde (CONASEMS) que foi proposta desse órgão a estratificação dos municípios em grupos, de modo que a avaliação não comparasse os menores e mais pobres com os maiores e mais ricos. Por isso, o programa distribuiu os municípios em seis grupos em função de indicadores relacionados justamente ao grau de desenvolvimento e porte populacional.

Sabemos também que ambos os fatores, embora mais fortemente o percentual de população pobre e extremamente pobre e de população residente em área rural, se correlacionam com a fixação de profissionais e estabilidade das equipes ${ }^{1}$, elementos decisivos para consolidação de um bom processo de trabalho. A dificuldade de fixar, sobretudo os médicos, e de cumprir efetivamente as prerrogativas da estratégia de saúde da família prevista na portaria 2.488 pode também ter desestimulado alguns gestores a aderirem ao programa com receio de que irregularidades fossem flagradas quando das visitas de avaliação externa, embora essa não seja uma função do programa.

Tais possibilidades foram antecipadas pelo CONASEMS de modo que, informalmente, fazia-se uma leitura que o aumento equitativo do $P A B$, que promoveu um aumento maior do valor do repasse per capita para os municípios menores e com piores indicadores socioeconômicos (PINTO et al., 2012), compensaria uma esperada baixa adesão dos mesmos ao PMAQ, e que, inversamente, o aumento menor no per capita concedido aos municípios maiores e mais ricos seria compensado pelo PMAQ.

Para nós não se trata de "compensação", pois concordamos com Pinto et al. (2012) e entendemos que o novo desenho de financiamento favorece, ao mesmo tempo, os municípios com maiores necessidades e aqueles que se esforçam e conseguem alcançar melhores resultados, um movimento não sendo oposto ou excludente do outro. Contudo entendemos que foi acertada a proposição do CONASEMS e arriscamos dizer que esta estratificação pode ter estimulado diversos município menores a participarem do programa pois, por mais que seja uma variação estatística considerável, não podemos dizer que 67,6\% e 69,7\% de adesão são números baixos. Assim, após os resultados da adesão concluímos que a antecipação do problema produziu uma solução que acreditamos que possa ter contribuído para minimizar sua manifestação concreta.

Outro indicador importante da adesão, nesse caso envolvendo além das gestões municipais também as $E A B$, é a quantidade e percentual de equipes que realizaram o processo de autoavaliação.

Quando verificamos os dados (tabela 04) referentes ao uso da ferramenta autoavaliativa disponibilizada pelo Ministério da Saúde, Autoavaliação para a Melhoria do Acesso e da Qualidade da Atenção Básica (AMAQ), notamos uma significativa utilização do instrumento. Mais de $75 \%$ das equipes de atenção básica que aderiram ao PMAQ utilizaram o AMAQ. Os

\footnotetext{
${ }^{1}$ Conforme estudo, ainda não publicado, realizado pelo DAB/Ministério da Saúde, utilizando a base do CNESS, e que gerou uma Nota Técnica que orientou a decisão de tomar esses parâmetros na definição de municípios e áreas prioritárias para o PROVAB e FIES.
} 
maiores percentuais de utilização do instrumento estão nos estados de Santa Catarina $(96,2 \%)$, Paraná $(88,5 \%)$, Minas Gerais $(86,7 \%)$ e Ceará $(86,1 \%)$.

Tabela 04 - Total de equipes que aderiram ao PMAQ, equipes que utilizaram oAMAQ e Percentual de equipes que utilizaram o AMAQ, por UF, Brasil, 2011

\begin{tabular}{|c|c|c|c|}
\hline UF & $\begin{array}{l}\text { Total de Equipes que } \\
\text { Aderiram ao PMAQ }\end{array}$ & $\begin{array}{l}\text { Equipes que } \\
\text { Utilizaram o AMAQ }\end{array}$ & $\begin{array}{l}\text { \% de Equipes que } \\
\text { Utilizaram o AMAQ }\end{array}$ \\
\hline$A C$ & 32 & 15 & 46,9 \\
\hline $\mathrm{AL}$ & 340 & 290 & 85,3 \\
\hline AM & 173 & 57 & 32,9 \\
\hline AP & 52 & 27 & 51,9 \\
\hline BA & 1.564 & 1.297 & 82,9 \\
\hline CE & 920 & 792 & 86,1 \\
\hline DF & 28 & 0 & 0,0 \\
\hline ES & 323 & 198 & 61,3 \\
\hline GO & 684 & 408 & 59,6 \\
\hline MA & 115 & 84 & 73,0 \\
\hline MG & 2.944 & 2.553 & 86,7 \\
\hline MS & 184 & 81 & 44,0 \\
\hline MT & 227 & 183 & 80,6 \\
\hline PA & 371 & 220 & 59,3 \\
\hline PB & 625 & 494 & 79,0 \\
\hline $\mathrm{PE}$ & 1.025 & 588 & 57,4 \\
\hline PI & 371 & 229 & 61,7 \\
\hline PR & 1.007 & 891 & 88,5 \\
\hline RJ & 1.071 & 539 & 50,3 \\
\hline RN & 411 & 316 & 76,9 \\
\hline RO & 98 & 69 & 70,4 \\
\hline RR & 35 & 19 & 54,3 \\
\hline RS & 829 & 704 & 84,9 \\
\hline SC & 1.108 & 1.066 & 96,2 \\
\hline SE & 273 & 226 & 82,8 \\
\hline SP & 2.323 & 1.636 & 70,4 \\
\hline TO & 299 & 136 & 45,5 \\
\hline Brasil & 17.432 & 13.118 & 75,3 \\
\hline
\end{tabular}

FONTE - Ministério da Saúde/Departamento de Atenção Básica

Esses números ficam mais impressionantes se levamos em conta alguns fatores. Como detalhamos acima, o AMAQ é um instrumento extenso, não é de realização simples e exige importante mobilização e articulação da $E A B$ e apoio da gestão municipal. Outro ponto muito 
relevante é que o $A M Q$, instrumento semelhante proposto anteriormente pelo $D A B$ e a partir do qual o AMAQ foi feito, em 6 anos foi utilizado por pouco mais de 2.500 equipes. Ou seja os números do AMAQ são 5 vezes maiores com um tempo 6 vezes mais curto.

A diferença fundamental não está no instrumento, embora existam, mas sim no contexto e na articulação do processo de autoavaliação com toda a estratégia proposta pelo PMAQ e debatida nesse artigo. Propor a autoavaliação como disparadora do processo de reflexão e de constituição do coletivo de mudança, enriquecê-la com o monitoramento, apoiar o coletivo através da educação permanente e apoio institucional com o objetivo de dar consequência prática àquilo que foi nomeado como problema no processo de autoavaliação e, por fim, reconhecer esse esforço na avaliação externa pode explicar em grande parte as diferenças de uso.

Contudo, em que pese o uso expressivo de uma ferramenta que foi ofertada e cujo uso é voluntário, é importante que se estude por que $25 \%$ não usou. Não usaram o AMAQ por que? Usaram outro instrumento? Apostaram em outro processo de constituição de coletivo e movimento? Perguntas a serem pesquisadas e respondidas em tempo para interferir nas próximas etapas do PMAQ.

\section{Considerações Finais}

O presente artigo procurou descrever as principais características e elementos constituintes do PMAQ, além de avaliar o processo inicial de sua implantação a partir da descrição de dados sobre a adesão dos municípios e das EAB.

Mostramos que o PMAQ se insere e se relaciona com o conjunto de estratégias prioritárias definidas pela Política Nacional de Atenção Básica e com outros movimentos mais amplos de reorientação do modo como se organiza o Sistema Único de Saúde, tais como o Decreto 7.508, de 29 de junho de 2011, a instituição de Redes de Atenção e o Programa de Avaliação para a Qualificação do SUS.

Em seguida, pudemos percorrer, ainda que de maneira panorâmica, pelas quatro fases que organizam a estrutura lógica do programa dando mais ênfase ao seu movimento dinâmico, às estratégias utilizadas para "fazer acontecer" que às às normas que estruturam o desenho de cada uma.

Vimos que a primeira fase, etapa de formalização da adesão ao programa possui como um de seus principais aspectos, o caráter voluntário da adesão, associado à ideia de que a qualificação do serviço e mudanças das práticas só se concretizarão em ambientes nos quais os trabalhadores, gestores e usuários sintam-se motivados e se percebam como atores centrais para o seu êxito constituindo para isso espaços de diálogo, negociação e gestão da mudança pactuada em cada contexto.

A segunda fase do PMAQ é compreendida como a etapa central do programa. A etapa de operação da mudança realizada fundamentalmente pelas $E A B$ e gestão municipal. Vimos que o desenho da segunda fase aposta na ampliação da capacidade de análise do coletivo, através das estratégias de autoavaliação e monitoramento, e no fortalecimento da capacidade de ação do mesmo, através dos suportes proporcionados pela educação permanente e apoio institucional. As quatro estratégias propostas se articulam para ampliar a capacidade de 
análise e de gestão de um coletivo que deve protagonizar a mudança das condições, relações e práticas.

Por sua vez, vimos que a terceira fase é o momento de realização da Avaliação Externa, na qual, a partir do levantamento de um conjunto de informações sobre as condições de acesso e de qualidade das $E A B$, se certificará as equipes participantes do programa, reconhecendo e valorizando os esforços e resultados obtidos pelas EAB e gestores municipais no processo de qualificação da $A B$. No processo de Avaliação Externa, as equipes serão avaliadas considerando elementos relacionados à gestão para o desenvolvimento da atenção básica; a estrutura e condições de funcionamento das UBS; a valorização dos trabalhadores; o acesso e qualidade da atenção e organização do processo de trabalho; e a utilização, participação e satisfação dos usuários.

A quarta fase é aquela em se pretende conectar tudo aquilo que foi desenvolvido durante as fases anteriores e aquelas que virão, a partir de um processo de retroalimentação no qual os avanços e entraves servem como balizadores para a recontratualização e seguimento do processo permanente de qualificação da atenção básica.

Finalmente, apresentamos algumas informações relacionadas ao processo de adesão e implantação do programa, a partir do uso da ferramenta autoavaliativa ofertada pelo Ministério da Saúde. Quanto a adesão, mostramos que, mesmo tendo menos de sessenta dias para a adesão, mais de $70 \%$ dos municípios brasileiros ingressaram no PMAQ, revelando uma adesão surpreendente para um programa novo, de adesão voluntária, que exigia uma série de prétarefas e de assunção de diversos compromissos para a adesão. Ao mesmo tempo, vimos que mais de $75 \%$ das equipes de atenção básica que aderiram ao PMAQ utilizaram o AMAQ, mostrando um expressivo interesse das equipes em utilizar instrumentos que permitam a identificação e o reconhecimento das principais necessidades, assim como dos principais avanços, relacionados ao movimento de ampliação do acesso e da qualidade da atenção básica.

\section{Referências bibliográficas}

ALTOÉ, Sonia (Org.). René Lourau: analista institucional em tempo integral. São Paulo: Hucitec, 2004.

BAREMBLITT, Gregório F. Compêndio de Análise Institucional e outras correntes: teoria e prática. Rio de Janeiro: Record, 1998.

BRASIL. Ministério da Saúde. Secretaria Executiva. Departamento de Monitoramento e Avaliação o SUS. Programa de Avaliação para Qualificação do Sistema Único de Saúde. Brasília, DF, 2011a.

BRASIL. Presidência da República. Decreto 7.508, de 28 de junho de 2011. Regulamenta a Lei no $\underline{8.080}$, de 19 de setembro de 1990, para dispor sobre a organização do Sistema Único de Saúde - SUS, o planejamento da saúde, a assistência à saúde e a articulação interfederativa, e dá outras providências. Diário Oficial da União, Brasília, DF, 29 de junho de 2011b. Disponível em: <http://www.planalto.gov.br/ccivil_03/_ato20112014/2011/decreto/D7508.htm>. Acesso em 25 jun. 2012. 
BRASIL. Ministério da Saúde. Portaria no 1.654, de 19 de julho de 2011. Institui, no âmbito do Sistema Único de saúde, o Programa Nacional de Melhoria do Acesso e da Qualidade da Atenção Básica (PMAQ-AB) e o Incentivo Financeiro do PMAQ-AB, denominado Componente de Qualidade do Piso de Atenção Básica Variável - PAB Variável. Saúde Legis, 2011. Disponível em: <http://bvsms.saude.gov.br/bvs/saudelegis/gm/2011/prt1654_19_07_2011.html>. Acesso em 25 jun. 2012.

BRASIL. Ministério da Saúde. Secretaria de Atenção à Saúde. Departamento de Atenção Básica. Programa Nacional de Melhoria do Acesso e da Qualidade da Atenção Básica (PMAQ): manual instrutivo. Brasília, DF: 2011d. Disponível em: <http://www.saude.mt.gov.br/upload/documento/165/pmaq-manual-instrutivo-\%5B165040412-SES-MT\%5D.pdf>. Acesso em 25 jun. 2012.

BRASIL. Ministério da Saúde. Secretaria de Atenção à Saúde. Departamento de Atenção Básica. Autoavaliação para a Melhoria do Acesso e da Qualidade da Atenção Básica: AMAQ. Brasília, DF, 2011e. Disponível em: <http://189.28.128.100/dab/docs/sistemas/Pmaq/amaq.pdf>. Acesso em 25 jun. 2012.

BRASIL. Ministério da Saúde. Secretaria de Atenção à Saúde. Departamento de Atenção Básica. Documento Síntese para Avaliação Externa do Programa Nacional de Melhoria do Acesso e da Qualidade da Atenção Básica (PMAQ). Brasília, DF, 2012a. Disponível em: <http://189.28.128.100/dab/docs/sistemas/pmaq/Documento_Sintese_Avaliacao_Externa_20 12_04_25.pdf>. Acesso em 25 jun. 2012.

BRASIL. Ministério da Saúde. Portaria no 866, de 03 de maio de 2012. Altera o prazo para solicitação da avaliação externa no Programa Nacional de Melhoria do Acesso e da Qualidade da Atenção Básica (PMAQ-AB) e as regras de classificação da certificação das equipes participantes do Programa. Saúde Legis, 2012. Disponível em: <http://bvsms.saude.gov.br/bvs/saudelegis/gm/2012/prt0866_03_05_2012.html>. Acesso em 25 jun. 2012.

BRASIL. Ministério da Saúde. Portaria no 1.089, de 28 de maio de 2012. Define o valor mensal integral do incentivo financeiro do Programa Nacional de Melhoria do Acesso e da Qualidade da Atenção Básica (PMAQ-AB), denominado como Componente de Qualidade do Piso de Atenção Básica Variável (PAB Variável). Saúde Legis, 2012. Disponível em: <http://bvsms.saude.gov.br/bvs/saudelegis/gm/2012/prt1089_28_05_2012.html>. Acesso em 25 jun. 2012.

CAMPOS, Gastão Wagner de Sousa. Um método para análise e co-gestão de coletivos. São Paulo: Hucitec, 2000.

CAMPOS, Gastão Wagner de Sousa. Saúde Paidéia. São Paulo: Hucitec, 2003.

CECÍLIO, Luíz Carlos de Oliveira. Contribuições para uma teoria da mudança do setor público. In: CECÍlIO, L. C. O. (Org.). Inventando a mudança na saúde. São Paulo: Hucitec, 1997.

CECÍLIO, Luíz Carlos de Oliveira. Uma sistematização e discussão de tecnologia leve de planejamento estratégico aplicada ao setor governamental. In: MERHY, E. E. (Org.). Agir em saúde. São Paulo: Hucitec, 2003. 
CECCIM, Ricardo Burg. Educação permanente em saúde: desafio ambicioso e necessário. Interface: comunicação, saúde, educação, São Paulo, v. 9, n. 16, p. 161-77, set. 2004/fev. 2005.

DELEuZE, G; GuATARRI, F. O Anti-Édipo: capitalismos e esquizofrenia. Lisboa: Assírio \& Alvim, 2003.

MATUS, Carlos. Política, planejamento e governo. Brasília: IPEA, 1993.

MERHY, Emerson Elias. Saúde: a cartografia do trabalho vivo. São Paulo: Hucitec, 2002.

PINTO, H. A., KOERnER, R. S.; SILVA, D. C. A. Prioridade se traduz em mais e melhores recursos para a atenção básica. Rede de Pesquisas em Atenção Primária à Saúde, Associação Brasileira de Saúde Coletiva. Disponível em <http://www.rededepesquisaaps.org.br/2012/06/18/prioridade-se-traduz-em-mais-emelhores-recursos-para-a-atencao-basica/> Acesso em 25 jun. 2012.

TESTA, Mário. Pensar em Saúde. Porto Alegre: Artmed, 1992. 